\title{
The distribution of three candidate cold-resistant SNPs in six minorities in North China
}

Qiuyan $\mathrm{Li}^{1,3+}$, Kexian Dong ${ }^{1 \dagger}$, Lidan $\mathrm{Xu}^{1}$, Xueyuan Jia ${ }^{1}$, Jie Wu${ }^{1}$, Wenjing Sun ${ }^{1}$, Xuelong Zhang ${ }^{1 *}$ and Songbin $\mathrm{Fu}^{1,2^{*}}$

\begin{abstract}
Background: Heilongjiang Province located in northeast China is a multi-ethnic region with people who have lived in cold conditions for several generations. Fatty acids are important to people with cold resistance. CPT1A encodes a protein that imports long-chain fatty acids into the mitochondria for fatty-acid oxidation. FADS is an essential enzyme for the synthesis of long-chain polyunsaturated fatty acids.

Results: In the present study, we investigated the distributions of three cold resistance-related SNPs (rs80356779 G > A in CPT1A, rs7115739 T > G in FADS3 and rs174570 C > T in FADS2) from six populations that included 1093 individuals who have lived in Heilongjiang Province for at least three generations. The frequencies of rs174570 and rs7115739 were different in our six north minorities compared to the Chinese Dai in Xishuangbanna (CDX) in southern China. All the SNPs in Hezhen were significantly different from other five studied populations. In addition, the genetic distribution of rs 174570 in Daur was significantly different from Manchu and Korea, and the frequency of rs7115739 in Ewenki was significantly different from the other populations. The results also showed that the frequencies of the three SNPs in the six minorities were different from those of Greenlandic Inuit and Siberian population.

Conclusions: Our results showed the distributions of the three cold resistance-related SNPs from six populations that included 1093 individuals in northern China. Distributions of the allele frequencies for the cold resistance-related SNPs in northern China were statistically different from those in southern China. These data help to establish the DNA genome database for the six populations and fully preserve existing minority genetic information.
\end{abstract}

Keywords: Minorities, CPT1A, FADS, SNP, North China

\section{Background}

Many studies have suggested that there are different genetic structures in different populations due to their complex demographic histories [1]. China is a multiethnic country with a long history of complex national integration and migration. These ethnic origins and mutual relations can be explored from various aspects, such as archeology, language, culture, physical characteristics, etc. Under same environmental condition, different populations can evolve to form similar physical characteristics. Although the size of the gene affected by the

\footnotetext{
* Correspondence: zhangxuel@ems.hrbmu.edu.cn;

zhangxuelonghyd@163.com; fusb@ems.hrbmu.edu.cn

${ }^{\dagger}$ Equal contributors

'Laboratory of Medical Genetics, Harbin Medical University, 157 Baojian Road, Nangang District, Harbin 150081, China

Full list of author information is available at the end of the article
}

environment is very small, it can be transmitted and stabilized from generation to generation to reflect important evolutionary events, forming the unique genetic diversity of the nation.

Having lived in northern China for a long period of time, Daur and other minorities have been subjected to cold climates. Thus, there may be some physiological differences contributing to their cold adaptations. Nonshivering thermogenesis is a physiological mechanism that generates body heat through mechanisms aside from mechanical shivering [2], and it may have been selected in humans who live in low-temperature regions under cold stress. Brown adipose tissue is an important site for non-shivering thermogenesis, which burns fat and uncouples mitochondrial oxidative metabolism from ATP production to produce heat [3]. It has been known that brown adipose tissue exists in mammalian infants. 
However, a recent study detected brown adipose tissue in distinct deposits in adult humans and interspersed in deposits of white adipose tissue. Since metabolic rates are known to be higher among humans living in extreme northern regions, metabolic rates in the non-shivering thermogenesis pathway in brown adipose tissue may have been subject to selection in response to cold stress [4].

Carnitine palmitoyltransferase 1 (CPT1) is a key regulatory enzyme that regulates fatty acid oxidation and has three isoforms, CPT1A, CPT1B and CPT1C. The CPT1A gene encodes a protein that imports long-chain fatty acids into the mitochondria for fatty acid oxidation. This mechanism is helpful for maintaining energy homeostasis when carbohydrate intake is insufficient [5]. CPT1B is expressed mainly in muscle. Different from CPT1A and CPT1B, CPT1C does not catalyze acyltransferase activity by using prototypic substrates [6]. Biochemical analyses using metabolomics-based screening strategies have clearly shown that mitochondrial activity is regulated by $\mathrm{CPT} 1$, and CPT1A is also a target for oxidative stress in human cells [7]. Ten missense variants were found in the carnitine acyltransferase gene family (CPT1A, CPT1B, CPT1C, CPT2, CRAT and CROT) that were related to fatty acid metabolism including CPT1A p.P479L (rs80356779). A study on Northeast Siberian populations showed that the CPT1A mutation conferred a metabolic advantage for Northeast Siberian populations for adaptation to their traditional high-fat diet [8].

The Fatty acid desaturase (FADS) genes, including FADS1, FADS2 and FADS3, code for enzymes that introduce double bonds at specific positions in a fatty acid chain [9]. In humans, the FADS genes are clustered within a 100-kb region on the long arm of human chromosome 11 (11q12-13.1) [10], which is a genomic cancer hot spot [11]. FADS1 (D5 desaturase) and FADS2 (D6/D8/D4-desaturase) have specificity for several fatty acid substrates [12-15]. FADS1 and FADS2 genes encode delta-5 desaturase (D5D) and delta-6 desaturase (D6D), respectively, which are essential enzymes for the synthesis of long-chain polyunsaturated fatty acids (LCPUFAs) [16]. FADS3 is a putative desaturase according to its sequence similarity with FADS1 and FADS2. The function of FADS3 is still unknown; however, its alternative transcripts can be directly upregulated by LCPUFAs via a PPAR $\gamma$-dependent mechanism independent of the regulation of FADS1 or FADS2 [17].

Previous study identified a missense mutation (rs80356779; c.1436C > T: p.P479U) in CPT1A as the most likely causative variant for positive selection in Northeast Siberians, using whole-genome high-coverage sequence data [8]. FADS genes have been confirmed to be under selection in Inuit who live under challenging conditions in the Arctic [18] and have been hypothesized in other populations [19], suggesting that FADS genes are keys in human adaptation to cold. Intron variants in FADS2 (rs174570; NM_001281501.1: c.142-8038C > T) and FADS3 (rs7115739; NM_021727.4: c.1287-380A > C) have been significantly associated with cold adaptation.

In the present study, we aimed to explore the distribution of three SNPs in six ethnic minorities. We hoped that these genetic resources could provide information on the origins of the human race, evolution, migration and other aspects.

\section{Methods \\ Study populations}

Six populations from Hezhen, Daur, Manchu, Korean, Mongolian, and Ewenki, totaling 1093 individuals from

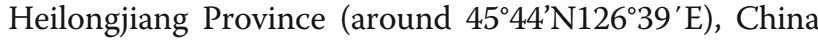
were included in the study (Additional file 1: Figure S1). Among them, the Daur, Manchu and Ewenki participants were recruited from Qiqihar city, and the Hezhen, Korean, Mongolian participants were recruited from Jiamusi city located in Heilongjiang Province. All ethnic residents in the selected communities were screened through face-to-face survey for identifying individuals who were from a family without inter-ethnic marriage in the last three generations. We invited those who met the criteria to participate in the study. The study protocol was approved by the ethics committee of Harbin Medical University and all participants provided written informed consent for participating the scientific research of population genetic study.

\section{DNA extraction and genotyping}

Genomic DNA was extracted from $200 \mu \mathrm{l}$ of whole blood using the QIAamp blood kit (Qiagen, Hilden, Germany) according to the manufacturer's protocol. The three cold resistance-related SNPs, rs80356779 G > A in CPT1A, rs7115739 $\mathrm{T}>\mathrm{G}$ in FADS3 and $\mathrm{rs} 174570 \mathrm{C}>\mathrm{T}$ in FADS2, were selected based on published articles $[8,18]$. Genotyping was performed using the SNPscan ${ }^{\text {TM }}$ Kit (Genesky Biotechnologies Inc., Shanghai, China) according to the manufacturer's instructions and based on a highthroughput SNP genotyping method utilizing double ligation and multiplex fluorescence PCR.

\section{Database data}

The genotype data of individuals from the three populations in China were downloaded from the 1000 genomes Project at https://www.ncbi.nlm.nih.gov/variation/ tools/1000genomes/. The three populations included following individuals: (1) 93 Han Chinese in Beijing (CHB) individuals in northern China (around $39^{\circ} 55^{\prime} \mathrm{N} 116^{\circ} 27^{\prime} \mathrm{E}$ ); (2) 103 Chinese Dai in Xishuangbanna (CDX) individuals in southern China (around $22^{\circ} 3^{\prime} \mathrm{N} 100^{\circ} 49^{\prime} \mathrm{E}$ ); and (3) 105 
Southern Han Chinese in China (CHS) individuals in southern China (around $30^{\circ} 22^{\prime} \mathrm{N} 103^{\circ} 26^{\prime} \mathrm{E}$ ).

\section{Statistical analysis}

Hardy-Weinberg equilibrium of the controls was calculated using the Chi-square test. Fst calculations were performed using POPGENE (version 1.32) to assess the genetic differences among the six populations. Shannon's information index was used to estimate the genetic diversity and the proportion of genetic variation within and between populations. The genotyping data have been submitted to Treebase under study number 22170 (https://treebase.org/treebase-web/user/summary.html? $\mathrm{id}=22170$ ). All statistical analyses were performed using the SPSS 23.0 software (IBM-SPSS, Inc., Chicago, IL, USA). A probability $(P)$ value $<0.05$ was considered statistically significant.

\section{Results}

\section{Genotyping data and Hardy-Weinberg test}

The allele frequencies of three SNPs are shown in Table 1. A total of 1093 individuals, including 146 Hezhen, 228 Daur, 212 Manchu, 244 Korean, 155 Mongolian and 108 Ewenki individuals were investigated. The genotype frequencies in the study are summarized in Table 1. The Chi-square test suggested that the three polymorphisms followed Hardy-Weinberg equilibrium in the overall population $(P>0.05)$.

\section{The frequencies of the polymorphisms among different populations}

As shown in Table 2, the heterozygosity statistics for all three SNPs were found to be highly similar among the Manchu, Korean and Mongolian individuals, showing that differences among the three populations were not significant. However, all the SNPs in the Hezhen population were significantly different from those in other five populations $(P<0.05)$. Daur were significantly different with Manchu and Korean regarding rs174570 genetic distribution $(P<0.05)$. The frequency of the rs7115739 polymorphism in Ewenki was significantly different from the other populations $(P<0.05)$.

We also compared the allele frequency distributions in the current minorities and other populations, including one

Table 1 The genotype distribution and Hardy-Weinberg equilibrium test for the three SNPs in six ethnic populations from China

\begin{tabular}{llllll}
\hline Locus & $\mathrm{AA}$ & $\mathrm{AB}$ & $\mathrm{BB}$ & Chi-square & $P$ value \\
\hline rs174570 & 392 & 527 & 174 & 0.016 & 0.900 \\
rs7115739 & 686 & 361 & 46 & 0.025 & 0.874 \\
rs80356779 & 1063 & 30 & 0 & 0.204 & 0.651 \\
\hline
\end{tabular}

$A A$ wild homozygote, $A B$ heterozygote, $B B$ mutant homozygote population located in northern China (CHB) and two located in southern China (CDX and CHS) (Additional file 2: Table S1). Tables 3 and (Additional file 2: Table S2) showed that the rs174570 and rs7115739 allele frequencies were different among the populations $(P<0.05)$. The frequencies of rs174570 ranged from 0.5000 to 0.7049 in six minorities. The frequencies in Korean and Manchu were similar, but different with other four minorities, and the frequencies of rs174570 were different in our six minorities from the CDX, which is the southeast population in this study. In addition, the frequencies of rs7115739 were different in the CDX when compared with most of our six minorities except for Hezhen, and there were strong differences between Hezhen and other populations in northern China, including Daur, Manchu, Korean and CHB $(P<0.05)$. The allele frequency in Korean was also different from that of other ethnic groups. However, in our six minorities, the A-allele in rs80356779 polymorphism was only detected in Hezhen, with the frequency of 0.1027.

\section{Analysis of population genetic structures}

As shown in Table 4, the Fst values of the SNPs among the six populations varied from 0.0160 to 0.0871 . According to analysis of gene diversity, the genetic differentiation Fst value among the populations was -0.0244 , which indicates that there was $97.56 \%$ genetic variation within the populations and that the genetic differentiation was low and found mainly within the population caused by individuals in each group. The average $\mathrm{Nm}$ was 9.9867, and large gene flow was the main reason for the low level of genetic differentiation. As shown in Table 5, the genetic distance among the populations ranged from 0.0011 to 0.0322 ; the genetic differentiation among the populations was not significant. The dendrogram produced with UPGMA based on Nei's genetic distances assessed the relationships among the populations (Fig. 1). The six populations were divided into two main branches, one comprised of four populations, including Hezhen, Daur, Mongolian and Ewenki, and the other comprised of two populations, Manchu and Korean.

\section{Discussion}

Molecular studies have been effective methods in exploring the geographic origins of humans in the last few decades. Populations living in the same region may have different origins but should have similar phenotypes due to the similar environment. A study detected the allele frequencies of SNPs in metabolic genes among 52 worldwide populations using the Bayesian likelihood test. Strong signals were found for FADS2 and FADS3, which are involved in lipid metabolism, suggesting a relationship between genetic variants and cold resistance [20]. CPT1 is 
Table 2 Summary of the heterozygosity statistics for all the loci in six ethnic populations from China

\begin{tabular}{|c|c|c|c|c|c|c|c|c|}
\hline Ethnic & Locus & Sample size & Obs_Hom ${ }^{d}$ & Obs_Het ${ }^{d}$ & Exp_Hom ${ }^{d}$ & Exp_Het $^{d}$ & Nei & Ave_Het ${ }^{\mathrm{C}}$ \\
\hline \multirow[t]{5}{*}{ Hezhen } & rs 174570 & 292 & 0.2877 & 0.7123 & 0.4983 & 0.5017 & 0.5000 & 0.4734 \\
\hline & rs7115739 & 292 & 0.4795 & 0.5205 & 0.5775 & 0.4225 & 0.4211 & 0.3370 \\
\hline & rs80356779 & 292 & 0.7945 & 0.2055 & 0.8150 & 0.1850 & 0.1884 & 0.0307 \\
\hline & Mean & 292 & 0.5205 & 0.4795 & 0.6302 & 0.3698 & 0.3685 & 0.2804 \\
\hline & St. Dev & & 0.2559 & 0.2559 & 0.1648 & 0.1648 & 0.1643 & 0.2267 \\
\hline \multirow[t]{5}{*}{ Daur } & rs174570 & 456 & $0.5044^{\mathrm{a}}$ & 0.4956 & 0.5049 & 0.4951 & 0.4940 & 0.4734 \\
\hline & rs7115739 & 456 & $0.6886^{a, c}$ & 0.3114 & 0.6960 & 0.3040 & 0.3033 & 0.3370 \\
\hline & rs80356779 & 456 & $1.0000^{\mathrm{a}}$ & 0.0000 & 1.0000 & 0.0000 & 0.0000 & 0.0307 \\
\hline & Mean & 456 & 0.7310 & 0.2690 & 0.7336 & 0.2664 & 0.2658 & 0.2804 \\
\hline & St. Dev & & 0.2505 & 0.2505 & 0.2497 & 0.2497 & 0.2491 & 0.2267 \\
\hline \multirow[t]{5}{*}{ Manchu } & rs174570 & 424 & $0.5849^{a, b}$ & 0.4151 & 0.5632 & 0.4368 & 0.4357 & 0.4734 \\
\hline & rs7115739 & 424 & $0.7217^{\mathrm{a}, \mathrm{c}}$ & 0.2783 & 0.6844 & 0.3156 & 0.3149 & 0.3370 \\
\hline & rs80356779 & 424 & $1.0000^{\mathrm{a}}$ & 0.0000 & 1.0000 & 0.0000 & 0.0000 & 0.0307 \\
\hline & Mean & 424 & 0.7689 & 0.2311 & 0.7492 & 0.2508 & 0.2502 & 0.2804 \\
\hline & St. Dev & & 0.2115 & 0.2115 & 0.2255 & 0.2255 & 0.2250 & 0.2267 \\
\hline \multirow[t]{5}{*}{ Korean } & rs174570 & 488 & $0.5902^{a, b}$ & 0.4098 & 0.5831 & 0.4169 & 0.4160 & 0.4734 \\
\hline & rs7115739 & 488 & $0.7377^{\mathrm{a}, \mathrm{c}}$ & 0.2623 & 0.7597 & 0.2403 & 0.2399 & 0.3370 \\
\hline & rs80356779 & 488 & $1.0000^{\mathrm{a}}$ & 0.0000 & 1.0000 & 0.0000 & 0.0000 & 0.0307 \\
\hline & Mean & 488 & 0.7760 & 0.2240 & 0.7809 & 0.2191 & 0.2186 & 0.2804 \\
\hline & St. Dev & & 0.2076 & 0.2076 & 0.2092 & 0.2092 & 0.2088 & 0.2267 \\
\hline \multirow[t]{5}{*}{ Mongolian } & rs174570 & 310 & $0.5419^{\mathrm{a}}$ & 0.4581 & 0.5037 & 0.4963 & 0.4947 & 0.4734 \\
\hline & rs7115739 & 310 & $0.6903^{a, c}$ & 0.3097 & 0.6354 & 0.3646 & 0.3635 & 0.3370 \\
\hline & rs80356779 & 310 & $1.0000^{\mathrm{a}}$ & 0.0000 & 1.0000 & 0.0000 & 0.0000 & 0.0307 \\
\hline & Mean & 310 & 0.7441 & 0.2559 & 0.7130 & 0.2870 & 0.2860 & 0.2804 \\
\hline & St. Dev & & 0.2337 & 0.2337 & 0.2571 & 0.2571 & 02563 & 0.2267 \\
\hline \multirow[t]{5}{*}{ Ewenki } & rs174570 & 216 & $0.5278^{\mathrm{a}}$ & 0.4722 & 0.4977 & 0.5023 & 0.5000 & 0.4734 \\
\hline & rs7115739 & 216 & $0.6019^{a}$ & 0.3981 & 0.6186 & 0.3814 & 0.3796 & 0.3370 \\
\hline & rs80356779 & 216 & $1.0000^{\mathrm{a}}$ & 0.0000 & 1.0000 & 0.0000 & 0.0000 & 0.0307 \\
\hline & Mean & 216 & 0.7099 & 0.2901 & 0.7055 & 0.2945 & 0.2932 & 0.2804 \\
\hline & St. Dev & & 0.2540 & 0.2540 & 0.2622 & 0.2622 & 0.2609 & 0.2667 \\
\hline
\end{tabular}

All data were calculated by POPGENE software

${ }^{\mathrm{a} C}$ Compared with Hezhen, $P<0.05$

${ }^{\mathrm{b}}$ Compared with Daur, $P<0.05$

${ }^{c}$ Compared with Ewenki, $P<0.05$

dObs_Hom: observed homozygosity; Obs_Het: observed heterozygosity; Exp_Hom: expected homozygosity; Exp_Het: expected heterozygosity; Ave_Het:

Average heterozygosity

the key enzyme in carnitine-dependent transport across the mitochondrial inner membrane, and its deficiency results in a decreased rate of fatty acid $\beta$-oxidation.

The six populations examined in this study have lived in Heilongjiang Province situated in northern China for hundreds of years; the climate in this area is very cold with temperatures below $-25{ }^{\circ} \mathrm{C}$ in the winter. The people who live here may have experienced cold adaptations and genetic variations that generate physiological differences through metabolic pathways. CPT1A and
FADS participate in the metabolism of fatty acids, which can store energy and heat for cold resistance. To live in a cold environment, people had to consume food containing much more fat in their daily diets. Furthermore, this has been reported in other cold-resistant populations. Therefore, CPT1A and FADS may be important factors for cold adaptation.

In this study, we investigated the diversity of cold resistance-related genes among six minorities from the northeast region of China to explore the hereditary 
Table 3 The $P$ values for rs174570 compared between six minorities in northern China and three populations in southern China

\begin{tabular}{llllllllll}
\hline Population & Hezhen & Daur & Manchu & Korean & Mongolian & Ewenki & CDX & CHB & CHS \\
\hline Hezhen & - & 2.150 & 23.271 & 32.845 & 1.607 & 0.011 & 34.346 & 10.398 & 0.011 \\
Daur & 0.143 & - & 26.918 & 38.388 & 1.707 & 0.003 & 38.657 & 11.341 & 3.438 \\
Manchu & $<0.001$ & $<0.001$ & - & 0.703 & 12.451 & 18.525 & 104.581 & 0.707 & 38.016 \\
Korean & $<0.001$ & $<0.001$ & 0.402 & - & 19.467 & 26.181 & 123.615 & 2.369 & 49.262 \\
Mongolian & 0.205 & 0.191 & $<0.001$ & $<0.001$ & - & 1.129 & 48.659 & 4.520 & 8.179 \\
Ewenki & 0.918 & 0.959 & $<0.001$ & $<0.001$ & 0.288 & - & 31.780 & 8.570 & 2.796 \\
CDX & $<0.001$ & $<0.001$ & $<0.001$ & $<0.001$ & $<0.001$ & $<0.001$ & - & 67.864 & 16.470 \\
CHB & 0.001 & 0.001 & 0.401 & 0.124 & 0.034 & 0.003 & $<0.001$ & - & 20.560 \\
CHS & 0.918 & 0.064 & $<0.001$ & $<0.001$ & 0.004 & 0.095 & $<0.001$ & $<0.001$ & - \\
\hline
\end{tabular}

Note: $X 2$ value (above diagonal) and $P$ value (below diagonal)

CDX Chinese Dai in Xishuangbanna, China, CHB Han Chinese in Beijing, China, CHS Southern Han Chinese

differences among six populations. We selected three SNPs from adipose metabolism-related genes for the analysis. We also compared the allele frequencies between our study cohort and other populations in China. The Chi-square test suggested that the three polymorphisms followed Hardy-Weinberg equilibrium in the overall populations, although the SNPs in several minorities deviated from HWE (not shown). We found that the frequencies of our six minorities were similar to $\mathrm{CHB}$, although there were some differences among them. However, when compared with populations located in southern China, great differences were observed. Since the CHB and six minorities are all located in northern China, and CHS and CDX are both located in southern China, the genetic differences between the $\mathrm{CHB}$ and six minorities are much smaller than those between the minorities and $\mathrm{CHS}$ and CDX. Thus, we presume that the gene may be undergoing strong selective pressures to resist cold and adapt to other environments. Additionally, there were strong differences between the six populations and the Greenlandic Inuit and Siberian population in allele frequencies. The allele frequencies of populations in northern China were in the middle of populations in southern China and Greenlandic Inuit and Siberian population, and there was a tendency to change with the latitude. In addition, Finnish in Finland (FIN) and British in England

Table 4 Summary of the F-Statistics and gene flow for all the loci

\begin{tabular}{llllll}
\hline Locus & Sample size & Fis & Fit & Fst & $\mathrm{Nm}^{\mathrm{a}}$ \\
\hline rs174570 & 2186 & -0.0432 & -0.0154 & 0.0267 & 9.1188 \\
rs7115739 & 2186 & -0.0288 & -0.0124 & 0.0160 & 15.4225 \\
rs80356779 & 2186 & -0.1145 & -0.0174 & 0.0871 & 2.6200 \\
Mean & 2186 & -0.0397 & -0.0143 & 0.0244 & 9.9867 \\
\hline
\end{tabular}

${ }^{\mathrm{a}} \mathrm{Nm}$ : Gene flow estimated from Fst $=0.25(1-\mathrm{Fst}) / \mathrm{Fst}$ and Scotland (GBR) who live in northern area with an latitude around $55^{\circ} \mathrm{N}$ were examined to find the frequencies of rs174570 and rs7115739 polymorphisms in the 1000 Genomes Project. The frequencies of rs174570 in FIN and GBR are 0.2525 and 0.1868 , respectively. The frequencies of rs7115739 in FIN and GBR are 0.9495 and 0.9505, respectively. These frequencies are very similar to those of Northeast Siberians and the Inuit, indicating that rs174570 and rs7115739 polymorphisms are associated with adaptation to cold. The results suggest that different minorities display unique genetic diversity in the nation during its long historical evolution for adapt to the cold environment.

The heterozygosity statistics for all three SNPs were found to be highly similar among Manchu, Korean, and Mongolian individuals, showing that the differences among the three populations were not significant. However, all the SNPs in the Hezhen population were significantly different from the other five populations. Daur was significantly different from Manchu and Korean with respect to the rs174570 genetic distribution. The frequency of the rs7115739 polymorphism in Ewenki was significantly different from the other populations. The differences may be associated with genetic drift.

Table $\mathbf{5}$ Nei's unbiased measures of genetic identity and genetic distance

\begin{tabular}{lllllll}
\hline Populations & Hezhen & Daur & Manchu & Korean & Mongolian & Ewenki \\
\hline Hezhen & - & 0.9897 & 0.9776 & 0.9683 & 0.9934 & 0.9952 \\
Daur & 0.0103 & - & 0.9931 & 0.9896 & 0.9988 & 0.9969 \\
Manchu & 0.0226 & 0.0070 & - & 0.9985 & 0.9920 & 0.9849 \\
Korean & 0.0322 & 0.0105 & 0.0015 & - & 0.9861 & 0.9773 \\
Mongolian & 0.0067 & 0.0012 & 0.0080 & 0.0140 & - & 0.9989 \\
Ewenki & 0.0048 & 0.0031 & 0.0152 & 0.0230 & 0.0011 & - \\
\hline
\end{tabular}

Note: Nei's genetic identity (above diagonal) and genetic distance (below diagonal) 


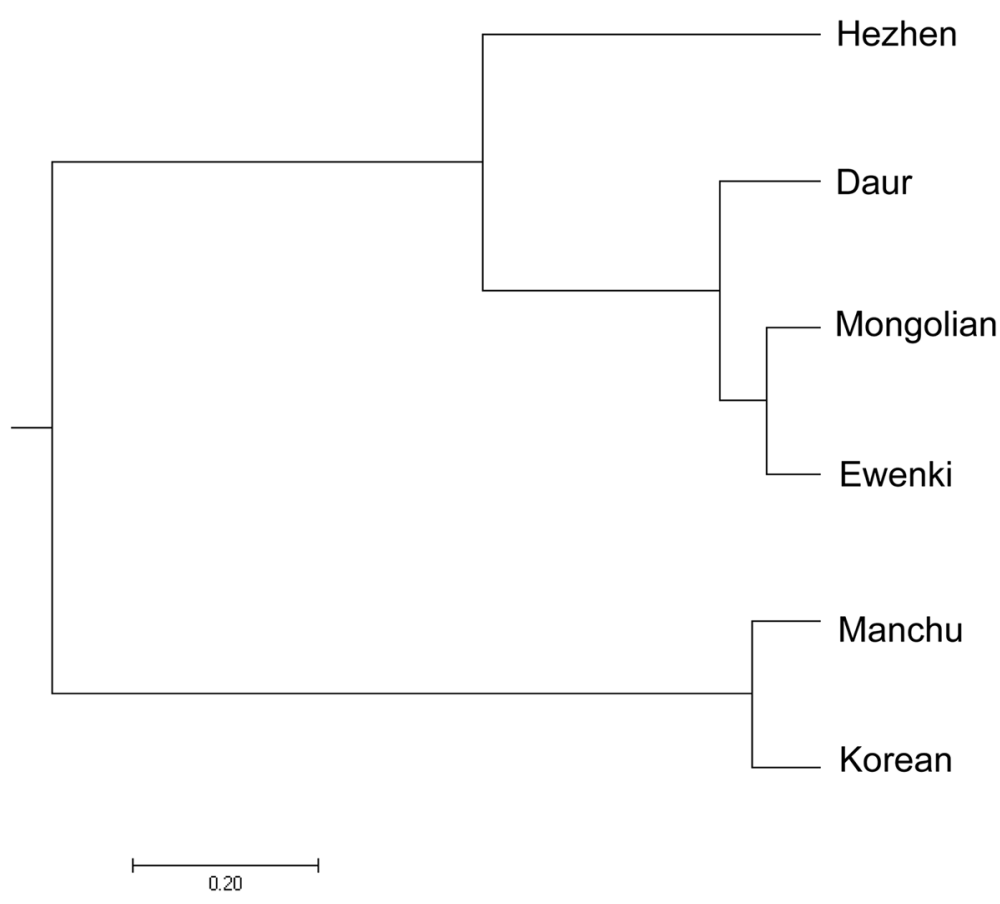

Fig. 1 Dendrogram based on Nei's genetic distance. The phylogenetic tree was created using a modified UPGMA method from the NEIGHBOR procedure in PHYLIP version 3.5

To measure the genetic differentiation, the Fst values were calculated for each SNP to quantify the differences among the populations. The results showed that the genetic differentiation among the populations was not significant. To assess the relationships among populations, a dendrogram was produced by UPGMA. The dendrogram divided the six populations into two main branches: one comprised of four populations, including Hezhen, Daur, Mongolian and Ewenki, and the other comprised of two populations, Manchu and Korean. The occurrence of this cluster relationship is consistent with a previous published study [21]. According to ancient literature, the Hezhen absorbed multi-ethnic elements as it was a nation of multi-sources; some clans even absorbed the Mongols. Recent studies have shown the genetic distance between the Hezhen nationality and Mongolians. The origin of the Daur population is called the theory of the "Mongolia branch." After establishment of P.R. China, the Ewenki divided from the Mongolians and formed a nation. However, the current cluster relationship still needs to be confirmed, which requires more genome data combined with archaeology data and population history for further analysis and verification.

\section{Conclusions}

In the present study, we investigated the distributions of three cold resistance-related SNPs from six populations that included 1093 individuals in northern China. Our results showed, for the first time, that the six minorities in northern China exhibit genetic differences in certain cold resistance-related genes when compared with each other and with southern Chinese populations, especially with CDX. These results highlight that ethnicity is a critical factor in the distribution of allele frequencies. Meanwhile, our study also contributed to the DNA genome database for the six populations.

\section{Additional files}

Additional file 1: Figure S1. The location of populations. The six minority populations from Hezhen, Daur, Manchu, Korea, Mongolian and Ewenki are located in Heilongjiang Province (around $45^{\circ} 44^{\prime} \mathrm{N} 126^{\circ} 39^{\prime} \mathrm{E}$ ). CHB indicates Han Chinese in Beijing (around39 $55^{\prime} \mathrm{N} 116^{\circ} 27^{\prime} \mathrm{E}$ ). CHS indicates Southern Han Chinese located in Sichuan province (around $30^{\circ}$ $22^{\prime} \mathrm{N} 103^{\circ} 26^{\prime} \mathrm{E}$ ). CDX indicates Chinese Dai in Xishuangbanna (around $22^{\circ}$ $3^{\prime} \mathrm{N} 100^{\circ} 49^{\prime} \mathrm{E}$ ). Greenlandic Inuit population live in area around $71^{\circ} 43^{\prime} \mathrm{N} 42^{\circ}$ $24^{\prime} \mathrm{W}$. Northeast Siberian population live in the northeast of Russia (around 78 $\left.50^{\prime} \mathrm{N} 112^{\circ} 50^{\prime} \mathrm{E}\right)$. (DOCX $109 \mathrm{~kb}$ )

Additional file 2: Table S1. The frequencies of three polymorphisms in 11 populations Table S2 The $P$ values for rs 7115739 compared between six minorities in northern China and three populations in southern China. (DOCX $16 \mathrm{~kb})$

\section{Abbreviations}

CDX: Dai in Xishuangbanna; CHB: Han Chinese in Beijing; CHS: Southern Han Chinese in China; CPT1: Carnitine palmitoyltransferase 1; FADS: Fatty acid desaturase 


\section{Acknowledgements}

We'd like to thank Dr. Yali Xue (Wellcome Trust Sanger Institute, Wellcome Genome Campus, Hinxton, Cambridge CB10 1SA, UK) for her advice and help.

\section{Funding}

This work was supported by the International Science \& Technology Cooperation Program of China (2013DFA31610 to S.F.), the National Key Research and Development Program of China (2016YFC1000504 to S.F.), and the National Natural Science Foundation of China (81373220).

\section{Availability of data and materials}

The genotype data of CHB, CDX, and CHS are available from the 1000 Genomes Project repository at https://www.ncbi.nlm.nih.gov/variation/tools/ 1000genomes/. The datasets used and/or analyzed during the current study are available from the corresponding author on reasonable request.

\section{Authors' contributions}

$\mathrm{QL}, \mathrm{KD}, \mathrm{WS}, \mathrm{XZ}$ and SF conceived and designed the study; QL, KD, LX, XJ, JW, WS, XZ and SF performed the experiments (DNA extraction and genotyping); $\mathrm{QL}, \mathrm{KD}, \mathrm{WS}, \mathrm{XZ}$ and SF analyzed the data; and QL, KD, WS, XZ and SF prepared the manuscript. All authors revised and approved the final draft.

\section{Ethics approval and consent to participate}

The study protocol was approved by Ethics Committee of Harbin Medical University and all experimental procedures (DNA extraction and genotyping) complied with the Declaration of Helsinki (2003). All participates gave written informed consent to take part in the present study.

\section{Consent for publication}

Not applicable.

\section{Competing interests}

The authors declare that they have no competing interests.

\section{Publisher's Note}

Springer Nature remains neutral with regard to jurisdictional claims in published maps and institutional affiliations.

\section{Author details}

'Laboratory of Medical Genetics, Harbin Medical University, 157 Baojian Road Nangang District, Harbin 150081, China. ${ }^{2}$ Key Laboratory of Medical Genetics, (Harbin Medical University), Heilongjiang Higher Education Institutions, 157 Baojian Road, Nangang District, Harbin 150081, China. ${ }^{3}$ Editorial Department of International Journal of Genetics, Harbin Medical University, Harbin, China.

Received: 16 November 2017 Accepted: 1 February 2018

Published online: 12 February 2018

\section{References}

1. Li JZ, Absher DM, Tang H, Southwick AM, Casto AM, Ramachandran S, Cann HM, Barsh GS, Feldman M, Cavalli-Sforza LL, et al. Worldwide human relationships inferred from genome-wide patterns of variation. Science. 2008;319(5866):1100-4

2. Seale $P$, Kajimura S, Spiegelman BM. Transcriptional control of brown adipocyte development and physiological function-of mice and men. Genes Dev. 2009;23(7):788-97.

3. Seale $P$, Lazar MA. Brown fat in humans: turning up the heat on obesity. Diabetes. 2009:58(7):1482-4.

4. Wong CC, Chen CC. A hybrid clustering and gradient descent approach for fuzzy modeling. IEEE trans syst Man Cybern Part B Cybern Publi IEEE Syst Man Cybern Soc. 1999;29(6):686-93.

5. Collins SA, Sinclair G, Mclntosh S, Bamforth F, Thompson R, Sobol I, Osborne G, Corriveau A, Santos M, Hanley B, et al. Carnitine palmitoyltransferase 1 A (CPT1A) P479L prevalence in live newborns in Yukon, northwest territories, and Nunavut. Mol Genet Metab. 2010;101(2-3):200-4.

6. Cirillo A, Di Salle A, Petillo O, Melone MA, Grimaldi G, Bellotti A, Torelli G, De' Santi MS, Cantatore G, Marinelli A, et al. High grade glioblastoma is associated with aberrant expression of ZFP57, a protein involved in gene imprinting, and of CPT1A and CPT1C that regulate fatty acid metabolism. Cancer Biol Ther. 2014;15(6):735-41.
7. Setoyama D, Fujimura Y, Miura D. Metabolomics reveals that carnitine palmitoyltransferase-1 is a novel target for oxidative inactivation in human cells. Genes Cells. 2013;18(12):1107-19.

8. Clemente FJ, Cardona A, Inchley CE, Peter BM, Jacobs G, Pagani L, Lawson DJ, Antao T, Vicente M, Mitt M, et al. A selective sweep on a deleterious mutation in CPT1A in Arctic populations. Am J Hum Genet. 2014;95(5):584-9.

9. Kothapalli KS, Ye K, Gadgil MS, Carlson SE, O'Brien KO, Zhang JY, Park HG, Ojukwu K, Zou J, Hyon SS, et al. Positive selection on a regulatory insertion-deletion polymorphism in FADS2 influences apparent endogenous synthesis of Arachidonic acid. Mol Biol Evol. 2016;33(7):1726-39.

10. Marquardt A, Stohr H, White K, Weber BH. cDNA cloning, genomic structure, and chromosomal localization of three members of the human fatty acid desaturase family. Genomics. 2000;66(2):175-83.

11. Park MH, Kim N, Lee JY, Park HY. Genetic loci associated with lipid concentrations and cardiovascular risk factors in the Korean population. J Med Genet. 2011:48(1):10-5.

12. Park HG, Kothapalli KS, Park WJ, DeAllie C, Liu L, Liang A, Lawrence P, Brenna JT. Palmitic acid (16:0) competes with omega-6 linoleic and omega-3 a-linolenic acids for FADS2 mediated Delta6-desaturation. Biochim Biophys Acta. 2016;1861(2):91-7.

13. Park HG, Park WJ, Kothapalli KS, Brenna JT. The fatty acid desaturase 2 (FADS2) gene product catalyzes Delta4 desaturation to yield n-3 docosahexaenoic acid and $n-6$ docosapentaenoic acid in human cells. FASEB J. 2015:29(9):3911-9.

14. Park WJ, Kothapalli KS, Lawrence P, Brenna JT. FADS2 function loss at the cancer hotspot 11q13 locus diverts lipid signaling precursor synthesis to unusual eicosanoid fatty acids. PLoS One. 2011;6(11):e28186.

15. Park WJ, Kothapalli KS, Lawrence P, Tyburczy C, Brenna JT. An alternate pathway to long-chain polyunsaturates: the FADS2 gene product Delta8-desaturates 20:2n-6 and 20:3n-3. J Lipid Res. 2009:50(6):1195-202.

16. Nakamura MT, Nara TY. Structure, function, and dietary regulation of delta6, delta5, and delta9 desaturases. Ann Rev Nutr. 2004;24:345-76.

17. Reardon HT, Hsieh AT, Park WJ, Kothapalli KS, Anthony JC, Nathanielsz PW, Brenna JT. Dietary long-chain polyunsaturated fatty acids upregulate expression of FADS3 transcripts. Prostaglandins Leukotrienes Essent Fatty Acids. 2013;88(1):15-9.

18. Fumagalli M, Moltke I, Grarup N, Racimo F, Bjerregaard P, Jorgensen ME, Korneliussen TS, Gerbault P, Skotte L, Linneberg A, et al. Greenlandic Inuit show genetic signatures of diet and climate adaptation. Science. 2015;349(6254):1343-7

19. Ameur A, Enroth S, Johansson A, Zaboli G, Igl W, Johansson AC, Rivas MA, Daly MJ, Schmitz G, Hicks AA, et al. Genetic adaptation of fatty-acid metabolism: a human-specific haplotype increasing the biosynthesis of long-chain omega-3 and omega-6 fatty acids. Am J Hum Genet. 2012;90(5):809-20

20. Hancock AM, Witonsky DB, Ehler E, Alkorta-Aranburu G, Beall C, Gebremedhin A, Sukernik R, Utermann G, Pritchard J, Coop G, et al. Colloquium paper: human adaptations to diet, subsistence, and ecoregion are due to subtle shifts in allele frequency. Proc Natl Acad Sci U S A. 2010;107(Suppl 2):8924-30.

21. Zerjal T, Xue Y, Bertorelle G, Wells RS, Bao W, Zhu S, Qamar R, Ayub Q, Mohyuddin A, Fu S, et al. The genetic legacy of the Mongols. Am J Hum Genet. 2003;72(3):717-21.

\section{Submit your next manuscript to BioMed Central and we will help you at every step:}

- We accept pre-submission inquiries

- Our selector tool helps you to find the most relevant journal

- We provide round the clock customer support

- Convenient online submission

- Thorough peer review

- Inclusion in PubMed and all major indexing services

- Maximum visibility for your research

Submit your manuscript at www.biomedcentral.com/submit
Biomed Central 